\title{
Editorial: Ten-year anniversary issue
}

\author{
Paolo Bertoldi
}

Published online: 14 December 2018

(C) Springer Nature B.V. 2018

In 2018, Energy Efficiency is 10 years old and to mark this important anniversary for the still relatively young but well-known journal, I would like to make some personal considerations on the evolution of energy efficiency in the last 10 years and on the specific and important contribution of this journal to the research and academic discussions on energy efficiency and the related policies.

Ten years ago, the climate change impact mitigation was becoming the main driver for energy efficiency policy action, while at corporate and private level, the main driver was the very high oil price (in 2008 the oil price reached a peak of 160 US\$) and energy efficiency was starting to be seen as strategy to mitigate the high oil prices.

In 2007, the climate change international policy area was regulated by the Kyoto Protocol (signed in 1997 and entered into force in 2005), which, though an interesting and potentially effective international policy instrument, unfortunately it covered only developed countries with modest mandatory emission cuts in the period 2008 to 2012 (compared for most country to the base year 1990). Under the Kyoto Protocol, the so called Flexible Instruments were introduced to foster international cooperation and technology transfer. Developing and in transition countries did not have emission reduction targets. Some of those countries such as China and other BRICS were soon to become the largest $\mathrm{CO}_{2}$ emitters. Energy efficiency was part of the Kyoto protocol measures and the subsequent discussions on a new international climate

P. Bertoldi $(\square)$

Energy Efficiency, Ispra, Italy

e-mail: paolo-bertoldi@libero.it frame and agreement to overcome the limits of the Kyoto Protocol. The negotiation to reach a new agreement based on common but differentiated responsibilities and a cooperative and participatory process was started at the Conference of the Parties (COP) in Bali in 2008.

In 2007, the IPCC released its Fourth Assessment Report (AR4) showing the scientific foundations of manmade $\mathrm{CO}_{2}$ emissions impact on the temperature increase compared to the pre-industrial period and the urgent need to mitigate emissions through a range of policies and technologies, including end-use energy efficiency, in particular on the building sector. The IPCC AR 4 key contribution to the climate change science was awarded the Nobel Price (several Energy Efficiency authors and members of Energy Efficiency Editorial Board were authors of the IPCC ARs). A special issue on IPCC AR 4 mitigation measures based on energy efficiency was published by Energy Efficiency in 2009 (Volume 2, Issue 4).

At the same time, energy efficiency policies were gaining momentum as a key climate mitigation strategy and, as indicated, also as part of national energy security actions to mitigate the impact of high energy prices or disruption to the energy supply, in particular for energy dependent regions such as the European Union. Researchers demonstrated that in OCCED countries the decoupling of energy consumption from GDP growth was the result of energy efficiency technologies and policies, and that the difference between the actual energy consumption and the energy consumption that would have happened without energy efficiency was the first energy source.

Focusing on Europe, in 2006, the European Union (EU) adopted a new overarching Directive, the Energy Service 
Directive (ESD), which gave a new boost to energy efficiency. The ESD requested the Member States to submit, starting in 2008 and every 3 years thereafter, a National Energy Efficiency Action Plan. Other recently adopted Directives (e.g. the Eco-design Directive introducing minimum efficiency requirements for energy consuming products and the Energy Performance of Building Directive (EPBD) introducing mandatory buildings code and energy performance certificates) were starting to deliver additional energy savings. Similar policies for energy efficiency in products and buildings were already in place in the other OECD countries (USA, Canada, Australia, etc.) and were starting to be implemented in most of the fast developing countries (in particular China, Brazil, Mexico).

As already indicated, private investors (large organisations, SMEs, and households) were demanding more efficient equipment and buildings and increased their investments in energy efficiency in response to very high energy prices, even if several barriers to investments in energy efficiency remained (this was a research topic of several articles published in Energy Efficiency). Energy Service Companies (ESCOs) were also emerging as a key vehicle to implement energy efficiency in particular in non-residential buildings.

During the decade, 2008 to 2018 , additional energy efficiency policies were introduced by an increasing number of countries. The EU adopted energy saving targets for $2020(-20 \%)$ in 2007 and for 2030 in 2018 (-35.5\%). In addition in the EU, the Energy Service Directive was strengthened and replaced by the Energy Efficiency Directive (EED) in 2012, introducing an annual energy saving target for energy companies (similar policies existed already in a few EU Member States such as the UK, Italy, France, Denmark, and in several US Statesthis has been the topic of a Special Issue published in 2008 (Volume 1, Issue 4)), in addition to other specific measures on metering, demand response, energy audits, financing, and energy services. The EPBD was recast in 2010 introducing the cost-optimal methodology to set mandatory building requirements and the concept of Nearly Zero Buildings for new buildings from 2020 onward. Energy efficiency standards were introduced for a range of appliances and equipment under the Ecodesign Directive. The strengthening of energy efficiency policies was also happening in Japan, China, Korea, Australia, the USA, where some States introduced very progressive and aggressive policies in addition to Federal policies for equipment, cars and buildings, and other OECD and transition countries (e.g. India, etc.).
In 2013, the IPCC published the fifth Assessment Report, which highlighted the urgency to limit temperature increase by the end of the century to $2{ }^{\circ} \mathrm{C}$, and analysed the scientific evidence of effective mitigation options in the various sectors (transport, energy, buildings, cities, and agriculture), including new efficiency technologies (e.g. LED lighting, super-efficient appliances), policies, financing, governance, and institutional capacity. It also highlighted that energy efficiency technology alone would not be enough to reduce energy consumption and $\mathrm{CO}_{2}$ emissions. The concept of energy conservation and energy sufficiency was investigated, in addition to technical efficiency. Also, the key role of consumers and end-users behaviour in social practices and every days choices in transport, purchase, and use of equipment was highlighted as a key research area to reduce consumption and emissions by influencing consumer behaviour, including the concept of nudging.

A key milestone in international negotiations to limit climate change was the Paris Agreement adopted in December 2015 and ratified by a large number of countries. Under the Paris Agreement, nations commit to contribute to limit temperature increase to well below $2{ }^{\circ} \mathrm{C}$ with the aim at stabilising the temperature increase to $1.5^{\circ} \mathrm{C}$ by the end of the current century. The Paris Agreement is based on a bottom up approach, where each nation commits to reduce emissions according to its capabilities and possibilities. Key to this process are the National Determined Contributions by each nation, which should, over the time, be strengthened in an interactive review and dialogue process.

Very recently, in October 2018, the IPCC released the Special Report on $1.5^{\circ} \mathrm{C}$, showing the urgency to limit (peaking) global emissions as soon as possible and to fast reduce them towards carbon neutrality by mid-century. Strong implementation of energy efficiency is present in all the IPCC scenarios reported in the Special Report, aiming at a global reduction of energy demand (which at the time is still growing!) at a different pace.

The Energy Efficiency journal contributed to the research and knowledge on policies, technologies, and progresses in climate and energy efficiency over its 10 years of history. Some key statistic and trends in the Energy Efficiency journal are presented in the article by Trianni et al. included in this issue. This article is based on a bibliometric analysis and shows the most important topics covered in the journal. I invite you to read the article.

As Editor-in-Chief of Energy Efficiency, I am proud that outstanding authors have published articles on key 
topics on energy efficiency in this journal, as described below, and in particular have focused on research and analysis of energy efficiency policies and policy evaluation (with some special issues dedicated to this very important topic, based on the conference IEPPEC (Volume 5, Issue 1), and (Volume 9, Issue 4) and ECEEE conferences), including randomised control trials, decomposition analysis, data envelopment analysis, and other econometric modelling. Other more specific areas of research with key contributions to current literatures by Energy Efficiency published articles include the following: Energy Service Companies (ESCOS) and Energy Performance Contracting; Market Based Instruments and Energy Company Obligations (with the very important Special Issue already mentioned), Consumer and Companies Behaviour in relation to energy and equipment use; Social Practices and Investments in energy efficiency (again with a recent Special issues (Volume 11, Issue 7) and several regular articles); Smart Meters and Energy Consumption Feed-back systems; Energy Performance of Buildings, including Net Zero Energy Buildings; Policies and programmes, including innovative instruments (e.g. industrial energy networks, energy audits, and energy management), with a focus on improv- ing energy efficiency in the industrial sector; efficiency improvements in vehicles and the diffusion of electric vehicles; and finally the role of local energy and climate initiatives, including transnational networks of cities.

To conclude, the energy efficiency landscape has changed a lot over the past 10 years mainly driven by climate change, with more awareness among policy makers on the role of energy efficiency in energy and climate policies and new areas of research (e.g. sufficiency).

I hope that Energy Efficiency is not only a key instrument for researchers in the energy efficiency area, but can also be seen by policy makers as a useful source to design, and implement and evaluate new and more effective policies for further improving energy efficiency, reducing energy consumption, fostering the adoption of renewable energy (through demand flexibility), promoting sustainable developments and universal energy access, and fighting climate change.

I conclude by thanking the Editorial Board, which has steered the journal over the past 10 years, and the many researchers that have published their research in Energy Efficiency. 